\title{
Diagnostic Methods of Microbial Pathogens
}

\section{Stefan Borgmann*}

Department of Clinical Infectiology and Infection Control, Hospital of Ingolstadt, D-85049 Ingolstadt, Germany

Within the past centuries laboratory diagnostic has rapidly evolved in a variety of fields, for instance in clinical chemistry. In comparison to clinical chemistry, microbiological diagnostic is relatively slow because time consuming bacterial growth is essential. Bacterial growth is necessary to obtain populations consisting of only one bacterial species, e.g., when samples are examined physiologically containing various species of microorganisms (respiratory secretions, etc.). Moreover, species identification commonly relies on the ability of microorganisms to metabolize energy sources, e.g. various sugars, and also these analyses are time consuming. Within the past years MALDI-TOF mass spectrometry (MALDI-TOF MS), previously used especially in research laboratories, has been developed right up to usage in commercial high throughput labs allowing acceleration of species identification even in routine diagnostics. Reich et al. [1] describe implementation of this new technique in a commercial lab for microbiological analyses. The authors also give a brief survey of the physical principles and summarize current developments in this area. However, a limitation of MALDI-TOF MS is the restricted capacity to perform antibiotic susceptibility testing.

Beside MALDI-TOF MS, flow cytometry might be a further tool to accelerate bacterial species identification as demonstrated in the article of Nuding and Zabel [2]. In opposition to MALDI-TOF MS, this technique enables antibiotic susceptibility testing. However, upto now this method only works in the hands of specialized experts.

Multi-resistant or highly pathogenic bacteria which are increasingly frequent affect humans causing severe infections which are difficult to treat. To intervene this development, knowledge is necessary about the mechanisms causing resistance and pathogenicity. Furthermore, information about the epidemiology of those bacteria is essential. Werner [3] describes modern methods of microbiological analyses aiding to elucidate these problems.

Although the above shown problems virtually are bad enough in researches analyzing infections caused by non-cultivable pathogens, the far going problems have to be resolved as well. Similar to most viral infections, diagnosis of toxoplasmosis and borreliosis bases on analyses of antibodies produced by the host organism as a consequence of infection. Gruber [4] describes current developments in diagnosis of borreliosis while Sagel and Krämer [5] focuses on the examination of toxoplasmosis.

The authors describe current laboratory test procedures but also conclude the latest knowledge about toxoplasmosis to an appropriate handling of the disease especially in regard to screening procedures.

Finally, Rahiem Ahmed [6] presents an interesting case of brucellosis. The diagnosis might take long and be difficult to find due to the diversity of symptoms of which multiples might be present but also only one or few: chills, sweating, night sweat, exhaustion, arthritis, muscle pain, hematological disorders.

The case report summarizes the variety of analyzes eventually leading to final diagnosis and appropriate treatment. The case happened in Saudi Arabia and in the Middle East region brucellosis is relatively common. However, in many developed countries, e.g. in Germany, brucellosis is a rare disease. Consequently, most physicians are not experienced with this disease and miss to imply it as a potential cause of a disorder of unknown origin. This is especially relevant for travellers returning from Middle East, for instance Turkey, and other regions with a high prevalence of brucellosis.

The editorial board invites authors to publish their results in the Journal of Bacteriology and Parasitology. At this, you will have the opportunity to learn about the exceptional tools of the OMICS group: digital books, audio listening, language translation, and social networking.

\section{References}

1. Reich M, Bosshard PP, Stark M, Beyser K, Borgmann S (2013) Species identification of bacteria and fungi from solid and liquid culture media by MALDI-TOF mass spectrometry. J Bacteriol Parasitol in press.

2. Nuding S, Zabel LT (2013) Detection, identification, and susceptibility testing of bacteria by flow cytometry. J Bacteriol Parasitol in press.

3. Werner G (2013) Molecular typing of Enterococci/VRE. J Bacteriol Parasitol in press.

4. Gruber R (2013) Multiplex bead based immunoassays for the serodiagnosis of lyme borreliosis. J Bacteriol Parasitol in press.

5. Sagel U, Krämer A (2013) Screening of maternal toxoplasmosis in pregnancy: laboratory diagnostics from the perspective of public health requirements. $J$ Bacteriol Parasitol in press.

6. Rahiem Ahmed YAA (2013) Rare Presentation of Brucellosis. J Bacteriol Parasitol in press.
*Corresponding author: Stefan Borgmann, Department of Clinical Infectiology and Infection Control, Hospital of Ingolstadt, D-85049 Ingolstadt, Germany, Tel: 0049 (0)841 8 80-2020; Fax: 0049 (0)841 8 80-2849; E-mail: stefan.borgmann@klinikum-ingolstadt.de, synlab@gmx.de

Received February 11, 2013; Accepted February 12, 2013; Published February 17,2013

Citation: Borgmann S (2013) Identification of Bacterial Pathogens Causing Prosthetic Joint Infections and Diagnostic Methods of Microbial Pathogens. J Bacteriol Parasitol S5-e001. doi:10.4172/2155-9597.S5-e001

Copyright: (c) 2013 Borgmann S. This is an open-access article distributed under the terms of the Creative Commons Attribution License, which permits unrestricted use, distribution, and reproduction in any medium, provided the original author and source are credited. 